\title{
Life, Liberty, and the Pursuit of Happiness: Measuring What Matters
}

\author{
Laura Musikanski \\ Happiness Alliance \\ Carl Polley \\ Kapiolani Community College
}

\begin{abstract}
This essay focuses on ways in which the governments of Bhutan and the United Kingdom are measuring subjective well-being as well as on how other governments including Norway, Spain, China, Canada, and New Zealand, are exploring the development of subjective wellbeing indicators. It concludes with recommended actions to aid in the formation of a consistent and comparable subjective well-being indicator for use by governments globally. The third in a series for which the purpose is to provide information to grassroots activists to foster the happiness movement for a new economic paradigm, this essay builds on the previous essays, Happiness in Public Policy and Measuring Happiness to Guide Public Policy: A Survey of Instruments and Policy Initiatives.
\end{abstract}

Keywords: gross national happiness, subjective well-being indicators, happiness policy, new economic paradigm, sustainability, quality of life metrics

\section{Introduction}

The U.S. Declaration of Independence (1776) claims the purpose of governments is to secure the rights that all people have to "Life, Liberty and the pursuit of Happiness" (p. 2). That declaration ushered in a new era for governments and peoples across the globe with aspirations of liberty and happiness. Until fairly recently, the idea of the American dream served as shorthand for each person's pursuit of their happiness and was generally seen as attainable. Yet, repeated economic downturns and crises have tarnished that image of an attainable goal for most Americans today (Economist, 2014). Putnam (2015) suggests that an "opportunity gap" has emerged in U.S. civil society, such that the American dream is now achievable only by the wealthy, while Clark (2015) argues that low social mobility in the United States illustrates how "the American dream was always an illusion" (p. 17). In the 20th century, at the national level of government in the United States, focus shifted away from the pursuit of happiness and toward quantified measures of success via economic indicators, while overlooking the actual status of well-being among the population. Yet, in the past 2 decades, a number of governments around the world have begun to focus explicitly on happiness and well-being. These governments have established a basis for fundamental changes in how they gauge the effectiveness of policies, by measuring directly the impact of policies on happiness and well-being. In this article, we review a number of approaches that nations around the world have taken toward the creation and use of happiness and well-being metrics in the 21st century. 


\section{What's Wrong With Gross Domestic Product?}

Gross domestic product (GDP) was born of the Great Depression, when the U.S. Congress was at a loss to understand how to bring the nation's economy back to a health. Simon Kuznets (1934) was hired to create the first measurement of national income, and he was the first to define GDP as the sum of all goods and services produced in a country in 1 year. The invention of this measurement successfully calibrated the progress of the U.S. economy's recovery from the Great Depression and was used again to great success during World War II to ensure war efforts did not leave the population unable to meet basic needs (Marcuss \& Kane, 2007). And yet, when Kuznets presented the measurement to Congress, he cautioned that "the welfare of a nation can scarcely be inferred from a measure of national income" (European Union, 2014). In 1968, well after both of these crises, Robert Kennedy (1968) lamented that

Too much and for too long, we seemed to have surrendered personal excellence and community values in the mere accumulation of material things. Our Gross National Product ... counts napalm and counts nuclear warheads ... It measures neither our wit nor our courage, neither our wisdom nor our learning, neither our compassion nor our devotion to our country, it measures everything in short, except that which makes life worthwhile. (p. 22)

Although governments continue to rely predominantly on GDP to guide economic policy (Cha, 2013), Stiglitz, Sen, and Fitoussi (2009) point out that an overreliance on GDP can mislead governments when it comes to actual well-being, leading to misguided policies. For example, a report commissioned by the United Nations found that the "creation and rapid diffusion of the [financial] crisis" (United Nations, 2009, p. 16) in 2008 was due in large part to an overemphasis by international institutions on measuring economic growth in purely monetary terms, which led to misguided deregulation of financial sectors and liberalization of capital markets in many countries (United Nations, 2009). A report issued that same year by a number of leading economists points out that GDP excludes certain assets, such as environmental resources and biodiversity, even though such noncommercial assets "play an important role in determining societal well-being" (Stiglitz et

al., 2009, p. 92). Stiglitz and colleagues (2009) echo the sentiment that an overemphasis on GDP has resulted in increasing income inequality, declining environmental sustainability, and decreasing leisure time in the United States. The factors that actually determine social and individual wellbeing "cannot be described as resources with imputable prices" (Stiglitz et al., 2009, p. 41).

\section{Beyond Gross Domestic Product}

The happiness movement brings happiness and well-being back into focus as key metrics for economic policy and social progress. The government of Bhutan is using happiness data to inform policy making (Musikanski, 2014), while international institutions are developing similar happiness metrics (Musikanski, 2015). Diener (2015) identifies 39 nations that have subjective well-being metrics: Austria, Australia, Belgium, Bhutan, Bulgaria, Canada, Chile, Cyprus, Czech Republic, Denmark, Estonia, Finland, France, Germany, Greece, Hungary, Iceland, Ireland, Italy, Japan, Latvia, Lichtenstein, Lithuania, Luxembourg, Malta, Mexico, Netherlands, New Zealand, Norway, Poland, Portugal, Romania, Slovakia, South Korea, Spain, Sweden, Switzerland, United Kingdom, 
and United States. Yet, most of these countries are at the early stages of measuring happiness and well-being with subjective metrics and have not yet endeavored to use the data for explicit policy purposes.

This essay focuses on several examples of national efforts to measure happiness. It does not cover the use of happiness data for policy purposes. The essay is not a conclusive exploration of national efforts to measure happiness. Happiness measurements, as used throughout the rest of this essay, are defined as subjective indicators of well-being that include questions about satisfaction with circumstances that impact one's life, affect, or eudemonia, or that use the term happiness to describe one's state of being.

\section{The State of National-Level Happiness Policy}

Understanding how to use happiness data for national-level policy is a major impediment to the happiness movement. Bhutan is exceptional in measuring and using happiness metrics in lieu of GDP. In Bhutan, the happiness measurement is called Gross National Happiness (GNH). Ura, Alkire, Zangmo and Wangdi (2012), on the use of the 2010 GNH Index in Bhutan, present the index as a tool by which the happiness of different cross-sections of the population can be compared with each other and tracked over time, offering policy makers clear information on who in Bhutan is and is not gaining from development and reform initiatives. Moreover, GNH can be used to understand some of the nuances of the population, because it identifies groups of people who fall within groups broadly defined as "unhappy, narrowly happy, extensively happy, and deeply happy" (Ura et al., 2012 , p. 39). Subsections of the populace by neighborhood, district, region, age, gender and even occupation can be analyzed separately, to ascertain the degree to which the distribution of happiness is equitable across the nation. Ultimately, the index is meant to offer a window on society as policymakers ask, "How can GNH be increased?" (p. 39).

Instead of using happiness data in lieu of GDP, policy makers in the United Kingdom are integrating happiness data into governmental agencies. (See Appendix A for examples of use of happiness data by governmental agencies in the United Kingdom.) In Great Britain, the happiness measurement is called the Measures of National Well-Being. The U.K. Office of National Statistics uses subjective well-being data to help both in measuring quality of life and in the formulation of policies and development of services (Office for National Statistics, 2014a). Because this well-being data allows for policies to target those populations that are in greatest need of improvement with regard to personal well-being, it provides a tractable method for balancing costs and benefits when considering revisions to policy (Office for National Statistics, 2014a). The Parliament of the United Kingdom (2014) is likewise exploring ways to use subjective well-being data for policy and programs focused on specific areas such as family services, volunteerism, and general policy.

\section{A Hypothetical Use of Subjective Indicators}

Subjective indicators can help decision makers by telling a different story than objective metrics can. A hypothetical use of subjective indicators in Bhutan follows. The national GNH 2010 results for the metric of mean annual household income by dzongkhag (region) show that the average income is less than half that of Thimphu, the national capital (Gross National Happiness, 2010, slide 451). However, according to subjective indicators of well-being, only $2.8 \%$ of people report not having enough income, while $29.4 \%$ say they have more than enough, compared to Thimphu, where $3.2 \%$ 
report not having enough and 29.6\% report having more than enough (Gross National Happiness, 2010, slide 464; see Appendix B for a comparison of Bhutan's GNH subjective and objective data). In light of this data, a policy maker may want to understand what practices, programs and other circumstances support a sense of economic well-being in areas of relatively lower income, which could transfer to other areas when forming economic policy.

\section{Happiness Measurements in Practice}

Bhutan and the United Kingdom use the happiness data they have collected in very different ways, primarily because of their different experiences with measuring the concept and cultural values. Another important reason for their different approaches is that they operate within entirely separate policy frameworks. While in Bhutan, GNH is defined as the primary measure to guide policy, in the United Kingdom, the goal is to use subjective well-being indicators in conjunction with GDP.

\section{Bhutan's Gross National Happiness}

Bhutan's 2010 GNH index is composed of 33 objective and subjective indicators that measure nine domains: psychological well-being, health, time use, education, cultural diversity and resilience, good governance, community vitality, ecological diversity and resilience, and living standards (Ura et al., 2012). Ura and colleagues recognize that using subjective well-being data to understand trends is complicated, largely due to "changes in the frame of reference" (p. 22). The 2010 GNH Index includes subjective indicators where there are no reasonable objective indicator alternatives, and the subjective data collected is helpful when used in combination with the objective data relevant to the matter measured (Ura et al., 2012).

\section{Bhutan's Subjective Indicators}

The subjective aspect of Bhutan's 2010 GNH Index is composed of 66 questions, comprising about $17 \%$ of the GNH Index, with between one and 22 questions per domain. Ten questions are about affect and emotional experience, including compassion, generosity, forgiveness, contentment, calmness, selfishness, jealousy, anger, fear, and worry (Ura et al., 2012). One question is asked regarding overall satisfaction with life: "How satisfied are you with the quality of your life?" (Ura et al., 2012, p. 125). Questions about satisfaction with health, standard of living, occupation, and family relationships are included to reduce bias, to address misunderstandings of wording, and to test internal consistency (Ura et al., 2012). Some questions are specific to the social and cultural context of Bhutan, such as how often one meditates, how the respondent would rate his or her knowledge and understanding of traditional songs, and how often did one experience feelings of compassion, forgiveness, and generosity (Ura et al., 2012).

Face-to-face interviews were conducted by the Centre for Bhutan Studies to gather the subjective data (Ura et al., 2012). In 2008, 950 people participated and, in 2010, 7,142 people participated, resulting in nationally representative sampling in both cases (Ura et al., 2012).

\section{Sufficiency Thresholds}

A population's happiness is rated according to predetermined sufficiency levels for each of the 33 indicators. Sufficiency thresholds determine "how much is enough to be happy," and they are measured on the basis of a combination of international and national standards, together with 
normative value judgments and participatory meetings (Ura et al., 2012). A level of $10 \%$ or below is deemed unhappy, between $10 \%$ and $66 \%$ is interpreted as narrowly happy, and these two groups together are considered "not yet happy," while the level between $67 \%$ and $77 \%$ is "extensively happy" and those above such a threshold are "deeply happy" (Ura et al., 2012, p. 23). Sufficiency thresholds guide policy makers in deciding which areas and groups to focus on in the goal of increasing Bhutan's GNH (Ura et al., 2012). In 2010, 59.1\% of the population was found to be not-yet-happy, and $40.9 \%$ was found to be happy (Ura et al., 2012). Based on their survey results, Ura and colleagues (2012) identified a single GNH Index value for 2010: 0.743), establishing a baseline by which to measure rates of change via future applications of the same measurement.

\section{Happiness Thresholds}

Bhutan is experimenting with the setting of individual happiness thresholds (Ura et al., 2012). If a person is below sufficiency (below 66\%) on six or more domains, they are deemed "unhappy" (Ura et al., 2012). Personal happiness thresholds are set to inspire discussion and debate among the citizenry, and to contribute to an understanding of the GNH Index by citizens as well as to the evolution of the index and its uses by the government (Ura et al., 2012).

\section{Future of Bhutan's GNH}

Regarding the continued use of happiness metrics, Ura and colleagues (2012) state that "The GNH Index, like the philosophy of GNH which motivates it, is very much a living experiment" (p. 63). Their recommendations, based on extensive analysis of the 2010 data, are to preserve and uphold the GNH culture of Bhutan, provide resources to individuals to increase their happiness and conduct regular surveys to monitor the status of the culture (Ura et al., 2012). Progress toward these recommendations was slowed in 2013 by the election of a new administration, but GNH nonetheless continues to play a central role in Bhutanese policy-making. Bhutanese Prime Minister Tshering Tobgay points out that

Bhutan is not a country that has attained GNH. Like most developing nations, we are struggling with the challenge of fulfilling the basic needs of our people. What separates us, however, from most others is that we have made happiness, the most fundamental of human needs, as the goal of societal change. (Gross National Happiness Commission, 2015, p. 8)

Bhutan's eleventh 5-year plan for 2013-2018 was issued by the Gross National Happiness Commission (2013). It lists "nation of GNH" (p. 42) as one of nine of the factors of the nation's competitive advantage and cites the GNH survey results from 2010 in addition to key performance indicators within the domains of happiness. In 2015, The Centre for Bhutan Studies (2015) announced that it has started gathering a new cohort of GNH data from " 8,871 randomly selected respondents" (p. 1).

\section{Great Britain's Measurements of National Well-Being}

Great Britain's Measures of National Well-Being are composed of objective and subjective measurements across ten areas: personal well-being, our relationships, health, what we do (employment, volunteerism, arts, culture, and sports), where we live (safety, the environment, transportation, and housing), personal finance, economy, education and skills, governance, and 
natural environment (pollution, energy consumption, recycling; Office of National Statistics, 2015). Snapshots of data trends for each indicator vary from 3 years running (2011-2013) for the subjective measures of personal well-being to a decade of data (2002-2012) for per capita income.

Areas involving subjective metrics include personal finance (satisfaction with income and finding difficulty with finances), governance (trust in government), our relationships (satisfaction with family life, social life and someone to rely on), health (satisfaction with health), and where we live (safety, sense of belonging in neighborhood, satisfaction with housing). The areas of personal wellbeing and what we do (satisfaction with job, leisure time, volunteerism and engagement in arts, culture and sports) are comprised of predominantly subjective indicators. (Office of National Statistics, 2014a; see Appendix C for an infographic depicting the subjective and objective data.) Personal well-being is measured with two questions about affect (happy, anxious) and two questions about satisfaction with life, both overall satisfaction and the worthiness of things one does (Office of National Statistics, 2015; see Appendix D for snapshots of the Office for National Statistic's personal well-being interactive 3-year dataset maps). Data for personal well-being is collected in the United Kingdom annually with face-to-face interviews and telephone interviews of about 165,000 people.

\section{Comparing Well-Being Scores}

The United Kingdom's Office of National Statistics provides data for the four questions measuring affect, life satisfaction, and worthwhile on interactive maps on a scale of $0-10$, where 7.3 was determined to be a threshold to life satisfaction (Office for National Statistics, 2014b). Scores can be compared by geographic region and other aspects of demographics, including a more personal approach to the well-being data provided on interactive bar charts, with averages for the four questions and trends over time (Office for National Statistics, 2014c).

\section{Brief Analysis of National Efforts}

The issuance of the Stiglitz et al. report and Bhutan's launch of the GNH Index have been followed by efforts by a number of governments around the world to explore the use of happiness (subjective well-being) indicators for measuring and informing policy. (See Appendix E: National Efforts Outside of Bhutan and the United Kingdom for an overview of national efforts by the governments of the Netherlands, France, Spain, Italy, China, New Zealand, Canada, United States, and Chile). The few countries that have been gathering subjective well-being data for years are starting to look at their data with a new lens. Spain is exploring the concept of single indicator index based on multiple variables, similar to Bhutan's single index for GNH. Other nations, including most notably the United Kingdom, are integrating surveys for happiness and well-being into government programs.

There is little conformity between countries, but most governments acknowledge that measuring and safeguarding the happiness and well-being of a population is the purpose of government, that outcomes are determined by metrics, and that a global accord for happiness and well-being metrics would be helpful. One of the main factors impeding progress toward a global metric for happiness and well-being is the lack of understanding of how such data could be used. The exploratory approaches taken by government agencies in the United Kingdom may ameliorate this problem.

Another issue is the level of resources needed to collect reliable subjective well-being data. Many governmental agencies lack clear methods for using subjective data and indicators or additional resources to collect the data (J. Hall, personal communication, October 6, 2014). Hall (2015) points to 
the lack of examples of happiness and well-being policies formulated because of subjective well-being data as an impediment to the collection and use of subjective well-being data by national level policy makers.

While other countries have started to collect data on subjective indicators, Bhutan (Musikanski, 2014) and the United Kingdom are showing the way for how such data could be used in policy making. (See Appendix A: United Kingdom's Use of Happiness Data for Public Policy for an explanation of how the United Kingdom is using data to inform policy.) Bhutan and the United Kingdom use happiness data differently. In Bhutan, happiness data guides the promulgation of national level policies. In the United Kingdom, small projects and programs within national and local government are informed by happiness data.

The ways these two countries measure happiness are more similar than different. Both nations use satisfaction with life, affect, and eudemonia measures in conjunction with subjective and objective measures for covering various domains or circumstances of life. These overlaps indicate there are many uses for happiness and well-being data for policymakers.

One of the main differences is that Bhutan's survey includes questions that measure the same aspects of subjective experience that the field of research in positive psychology measure, providing a research-driven basis for integrating personal happiness with policy. Success in this type of approach fosters a connection in the individual to his or her community and country. Some worry that the government will overly interfere in personal, moral and social decisions through monitoring, legislation and enforcement if happiness is considered for policy purposes (Marks \& Thompson, 2008). In the words of John Adams (1776), "happiness of society is the end of government" (p. 4). If the purpose of measuring happiness is to measure how policies contribute to the sustainability, equity, and well-being of all, then it is important to connect individual subjective indicators with concepts of social progress. Well-being and happiness could aid individuals and countries in taking practical steps toward improving levels of compassion, love, and care for all.

\section{Recommendations}

To further the happiness movement and the transition whereby happiness becomes the key metric for economic policy and social progress, it is important that nations continue to explore the development of happiness and well-being indicators in a way that meets the needs of each country according to its individual circumstances and contributes to dialogue among nations. The following five recommendations would support this approach:

1. International institutions should collect subjective well-being data at the national, state, and neighborhood levels, including a measure of satisfaction with life such as the Cantril ladder, affect, and eudemonia, as well as satisfaction with multiple domains or conditions of life and other aspects of subjective well-being and make this data easily available to other nations as well as states, state, city, and rural governments, community-based agencies, and grassroots activists.

2. National, state, city, and rural governments should be guided by international institutions working toward consensus, thereby allowing for comparability in measurement and management of well-being for national-level subjective well-being 
indicators when measuring satisfaction with life, affect, and eudemonia (Musikanski, 2015).

3. National governments should share as explicitly as possible their methods used when developing and determining their subjective well-being indicators, as well as their processes for data collection process. Data collected should be shared with other nations as well as states, state, city, and rural governments, community-based agencies, and grassroots activists in an open and transparent manner.

4. National governments should work with international institutions, community-based research agencies, and grass-roots activists in collecting subjective well-being data and using such data to inform policy. They should use subjective well-being data within national governmental agencies and in conjunction with state, city, and rural governmental agencies that work in concert with community-based agencies and grassroots activists.

5. National governments should share as clearly as possible the processes used for collecting subjective data, and should be open about how such data are used to inform public policy. They should also share information and stories about related outcomes, including both failures and successes, with other nations as well as states, state, city, and rural governments, community-based agencies, and grassroots activists in an open and transparent manner.

\section{Conclusion}

Since 2008, the measurement of subjective indicators of well-being to influence public policy has spread from Bhutan, in varying manifestations, to New Zealand, Great Britain, and to other nations that have, to date, been generally exploratory, as government agencies begin to experiment with data gathering and ways in which such data can inform public policies. While Bhutan has been active in spreading the concept of GNH, and it has been the only country with a history of enacting policies explicitly based on happiness (Musikanski, 2014), it has not been active in discussing examples of how such data interacts with policy making. Examples of how subjective well-being data are applied by the United Kingdom's governmental agencies are forthcoming, and they are likely to pick up where Bhutan left off in spreading international awareness of subjective well-being indicators, thereby propelling forward the happiness movement and a paradigm shift in what we measure, what we value, and ultimately, the outcomes we choose for our lives and for the planet, moving the focus away from a system that measures material wealth toward one that measures happiness and well-being.

\section{References}

Adams, J. (1776, April). John Adams, thoughts on government. In Taylor, Robert J. et al., eds. (1977). Papers of John Adams (Papers 4, pp. 86-93). Cambridge, MA: Harvard University Press.

Argueso, A., Escudero, T., Mendez, J., \& Izquierdo, M. (2013, January). Alternatives in the construction of a multidimensional quality of life indicator. Instituto Nacional de Estadistica. Retrieved from 
http://www.ine.es/ss/Satellite?blobcol=urldata\&blobheader=application\%2Fpdf\&blobheadern ame1=Content-Disposition\&blobheadervalue1=attachment\%3B+filename\%3Ddoc1-

2013_en.pdf\&blobkey=urldata\&blobtable $=$ MungoBlobs\&blobwhere $=152 \% 2 \mathrm{~F} 287 \% 2 \mathrm{Fdoc} 1$ -

2013_en\%2C0.pdf\&ssbinary=true

Brown, D., Woolf, J., \& Smith, C. (2010). The determinants of subjective wellbeing in New Zealand: An empirical look at New Zealand's social welfare function. Statistics New Zealand.

Retrieved from http://www.stats.govt.nz/ /media/Statistics/surveys-and-

methods/methods/research-papers/NZAE/2010/The-determinants-of-subjective-wellbeing.pdf

Cha, M. (2013, January 29). What's missing from GDP? Retrieved from http://www.demos.org/publication/whats-missing-gdp

Chen, Z., \& Davey, G. (2008). Happiness and subjective wellbeing in mainland China. Journal of Happiness Studies, 9 , 589-600. doi:10.1007/s10902-008-9092-7

Chrisafis, A. (2010, November 17). Measuring happiness, the French way. The Guardian. Retrieved from http://www.theguardian.com/world/2010/nov/17/france-happiness-index

Clark, G. (2015). The American dream is an illusion. Foreign Affairs. Retrieved from https://www.foreignaffairs.com/articles/united-states/2014-08-26/american-dream-illusion

Diener, E. (2015, October 16). The remarkable advances in the science of wellbeing. Speech presented at the International Society for Quality of Life Standards, Phoenix, AZ.

Davey, G., \& Rato, R. (2012). Subjective wellbeing in China: A Review. Journal of Happiness Studies, 13, 333-346. doi:10.1007/s11205-010-9766-5

Economist. (2014, February 1). Mobility, measured: America is no less socially mobile than it was a generation ago. Retrieved from http://www.economist.com/news/united-states/21595437america-no-less-socially-mobile-it-was-generation-ago-mobility-measured

European Union. (2014). Beyond GDP measuring progress, true wealth and the wellbeing of nations key quotes. Retrieved from http://ec.europa.eu/environment/beyond_gdp/key_quotes_en.html

GOV.UK. (2013, July 23). Wellbeing: policy and analysis. Cabinet Office. Retrieved from https://www.gov.uk/government/publications/wellbeing-policy-and-analysis

GOV.UK. (2014). Wellbeing why it matters to health policy. Department of Health. Retrieved from https://www.gov.uk/government/publications/wellbeing-and-health-policy

Gross National Happiness. (2010). 2010 survey results. Retrieved from http://www.grossnationalhappiness.com/survey-results/index

Gross National Happiness Commission. (2013). Eleventh five year plan, Volume 1: main document. Retrieved from http://www.gnhc.gov.bt/

Gross National Happiness Commission. (2015). FAQ on gross national happiness (GNH). Retrieved from http://www.gnhc.gov.bt/2013/04/faq-on-gross-national-happiness-gnh/

Hall, J. (2015, October 15). Strategic challenges in measuring progress: integration, application and global research. Speech presented at Organization on Cooperation and Economic Development 5th World Forum Transforming Policy: Changing Lives. Guadalajara, Mexico. 
House of Commons Environmental Audit Committee. (2013-2014). Wellbeing: fifteenth report of session 2013-14. Retrieved from http://www.parliament.uk/business/committees/committeesa-z/commons-select/environmental-audit-committee/news/wellbeingreportpublication/

INEGInforma. (2014a). Subjective wellbeing and public policy: Examples and potential uses (Macro) - B - (English audio). Retrieved from http://www.youtube.com/watch?v=_57FFEYke64\&list=UUvFp7Fse31ECLPYA4g9xD9A

INEGInforma. (2014b). Subjective wellbeing and public policy: examples and potential uses (Meso) B - (English audio). Retrieved from http://youtu.be/ibitjcj0TlY

INSEE. (2014). Economic performance and social progress - following up on the Stiglitz report. Retrieved from http://www.insee.fr/en/publications-etservices/default.asp?page=dossiers_web/stiglitz/performance_eco.htm

INSEE. (2011, October). Life satisfaction: French people give themselves and average score of 7 out of 10. Retrieved from http://www.insee.fr/en/publications-etservices/dossiers_web/stiglitz/VE4-Anglais.pdf

Istat. (2013). First report on equitable and sustainable wellbeing (BES). Retrieved from http://www.istat.it/en/archive/84498

Istat. (2014). Equitable and sustainable wellbeing in Italy summary (BES). Retrieved from http://www.istat.it/en/archive/84498

Istat \& CNEL. (2013). BES 2013. Retrieved from http://www.istat.it/en/files/2013/03/BesSummary.pdf?title

Kennedy, R. (1968, March 18). Speech delivered at the University of Kansas, Lawrence, Kansas. Retrieved from http://www.jfklibrary.org/Research/Research-Aids/Ready-Reference/RFKSpeeches/Remarks-of-Robert-F-Kennedy-at-the-University-of-Kansas-March-18-1968.aspx

Knight, J., \& Gunatilaka, R. (2010). The rural-urban divide in China: Income but not happiness? Journal of Development Studies, 46 , 506-534. doi:10.1080/00220380903012763

Kuznets, S. (1934). National income, 1929-1932. National Bureau of Economic Research, 49. Retrieved from http://www.nber.org/chapters/c2258.pdf

Lallanilla, M. (2012, December 20). Happiest nations on earth revealed [Web log post]. Retrieved from http://www.livescience.com/25713-happiest-countries-happiness-gallup.html

Lai, D. (2003). Principal component analysis on human development indicators of China. Social Indicators Research, 61, 319-330. doi:10.1023/A:1021951302937

Marcuss, R. D., \& Kane, R. (2007). U.S. national income and product statistics born of the great depression and World War II. Survey of Current Business 97, 32-45. Retrieved from http://www.bea.gov/scb/pdf/2007/02\%20February/0207_history_article.pdf

Miao, Y. (2003). Happiness in the field of psychology: Research into the theory and measurement of well-being. (Unpublished doctoral thesis). Nanjing Normal University (in Chinese).

Marks, N., \& Thompson, S. (2008, October 22). Measuring wellbeing in policy. Retrieved from http://www.neweconomics.org/publications/entry/measuring-well-being-in-policy

Musikanski, L. (2014). Happiness in public policy. Journal of Social Change, 6, 55-85. Retrieved from http://scholarworks.waldenu.edu/jsc/vol6/iss1/5/ 
Musikanski, L. (2015). Measuring happiness to guide public policy making: A survey of instruments and policy initiatives. Journal of Social Change, 5, 39-55. Retrieved from http://scholarworks.waldenu.edu/jsc/vol7/iss1/3/

National Research Council (U.S.) Panel on measuring subjective well-being in a policy-relevant framework. (2012). The subjective wellbeing module of the American Time Use Survey: Assessment for its continuation background and overview. Washington, DC: National Academies Press. Retrieved from http://www.ncbi.nlm.nih.gov/books/NBK110137/

Office for National Statistics. (2014a). Measuring national wellbeing: Insights across society, the economy and environment. Retrieved from http://www.ons.gov.uk/ons/rel/wellbeing/measuring-national-well-being/reflections-onmeasuring-national-well-being--may-2014/info-insights-across-society.html

Office for National Statistics. (2014b). Personal wellbeing interactive map. Retrieved from http://www.neighbourhood.statistics.gov.uk/HTMLDocs/dvc124/wrapper.html

Office for National Statistics. (2014c). Personal wellbeing interactive chart. Retrieved from http://www.neighbourhood.statistics.gov.uk/HTMLDocs/dvc107/index.html

Office for National Statistics. (2015). Personal wellbeing three year data-set maps (interactive and static). Retrieved from http://www.ons.gov.uk/ons/rel/wellbeing/measuring-national-wellbeing/personal-well-being-in-the-uk--three-year-data-2011-2014/rpt-personal-well-being2.html\#tab-Interactive-maps

OPHI. (2015a). Missing dimensions of poverty survey in Chile. Retrieved from http://www.ophi.org.uk/research/missing-dimensions/projects/chile/

OPHI. (2015b). Survey other dimensions of household quality of life. Retrieved from http://www.ophi.org.uk/wp-content/uploads/Translation-

Chile_survey_final_English.pdf?0a8fd7

Parliament of the United Kingdom. (2014). Wellbeing: Environmental audit committee contents wellbeing. Retrieved from http://www.publications.parliament.uk/pa/cm201314/cmselect/cmenvaud/59/5906.htm\#a4

Putnam, R. D. (2015). Our kids: The American dream in crisis. New York, NY: Simon \& Schuster.

Rojas, M., \& Martinez, I. (2012). Measurement, research and inclusion in public policy of subjective wellbeing: Latin America. Scientific and Technological Consultative Forum, Civil Association. Retrieved from http://www.academia.edu/2956806/Measurement_Research_and_Inclusion_in_Public_Policy_ of_Subjective_Wellbeing_Latin_America

Siebens, J. (2013, September). Extended measures of wellbeing: Living conditions in the United States: 2011 Retrieved from http://www.census.gov/prod/2013pubs/p70-136.pdf

Statistics Canada. (2013, October 11). Main article. Retrieved from http://www.statcan.gc.ca/pub/11f0019m/2013351/part-partie1-eng.htm

Statistics Netherlands. (2012, March 23). Participation in social activities. Retrieved from http://statline.cbs.nl/StatWeb/publication/?VW=T\&DM=SLEN\&PA=60027eng\&D1=43$52 \& \mathrm{D} 2=1-2 \& \mathrm{D} 3=0-12 \& \mathrm{HD}=130221-1547 \& \mathrm{LA}=\mathrm{EN} \& \mathrm{HDR}=\mathrm{G} 2 \& \mathrm{STB}=\mathrm{G} 1, \mathrm{~T}$ 
Statistics Netherlands. (2015, January 16). Wellbeing; economic risks, 2003-2012. Retrieved from http://statline.cbs.nl/Statweb/publication/?DM=SLEN\&PA=81465eng\&D1=0-1\&D2=a\&D3=0$2 \& \mathrm{D} 4=8-9 \& \mathrm{LA}=\mathrm{EN} \& \mathrm{VW}=\mathrm{T}$

Statistics New Zealand. (2009a). New Zealand general social survey: 2008-Hot off the press. Retrieved from http://www.stats.govt.nz/browse_for_stats/people_and_communities/Households/nzgss_HOTP 2008.aspx

Statistics New Zealand. (2009b). New Zealand general social survey. Retrieved from http://www.stats.govt.nz/browse_for_stats/people_and_communities/Households/nzgss_HOTP 2008.aspx

Statistics New Zealand. (2015). New Zealand general social survey: Information releases. Retrieved from http://www.stats.govt.nz/browse_for_stats/people_and_communities/Well-being/nzgssinfo-releases.aspx

Stiglitz, J., Sen, A., \& Fitoussi, J. (2009, September). Report by the Commission on the Measurement of Economic Performance and Social Progress. Retrieved from http://www.stiglitz-senfitoussi.fr/documents/rapport_anglais.pdf

The Centre for Bhutan Studies. (2015). The Centre has started the nation wide GNH survey from 2nd January 2015 [Facebook post]. Retrieved from https://www.facebook.com/cbsandgnhr?fref=nf

United Nations. (2009, September 21). Report of the Commission of Experts of the President of the United National General Assembly on Reports of the International Monetary and Financial System, 63rd session. Retrieved from http://www.un.org/ga/econcrisissummit/docs/FinalReport_CoE.pdf

United States Census Bureau. (2012). About wellbeing. Retrieved from http://www.census.gov/hhes/well-being/about/

Ura, K., Alkire, S., Zangmo, T., \& Wangdi, K. (2012). An extensive analysis of GNH index. Centre for Bhutan Studies. Retrieved from http://www.grossnationalhappiness.com/wpcontent/uploads/2012/10/An\%20Extensive\%20Analysis\%20of\%20GNH\%20Index.pdf

U.S. Declaration of Independence, Paragraph 1 (1776).

van Beuningen, J., \& de Jonge, T. (2011). The personal wellbeing index. Construct validity for the Netherlands. Central Bureau voor de Statistiek Den Haag, Harleen. Retrieved from http://www.cbs.nl/NR/rdonlyres/F0C01716-3E08-4A6E-AC309234A5EFC5FD/0/2011x1024art.pdf

van Beuningen, J., van der Houwan, K., \& Moonan, L. (2014). Measuring wellbeing. Statistics Netherlands. Retrieved from http://www.cbs.nl/NR/rdonlyres/FF644A99-580C-4D7E-B214BEE54A947D46/0/Measuringwellbeing.pdf

Xing, Z., \& Huang, L. (2007). A study on subjective quality of life among current Chinese primary social groups. Social Sciences in Nanjing, 1, 83-97 (in Chinese). 


\section{Appendix A}

\section{United Kingdom's Use of Happiness Data for Public Policy}

Subjective indicators of well-being, or "personal well-being data," are being used by many departments in the United Kingdom both for policy formation and for policy analysis (Office for National Statistics, 2014a). To coordinate such efforts, the U.K. Department of Health has issued a well-being toolkit, Well-being: Why It Matters to Health Policy, explaining the importance of subjective well-being for policy makers (GOV.UK, 2014), how funding is being allocated to local authority well-being boards, and how policy makers can use the data.

Many governmental agencies are exploring the use of well-being data to measure impacts of policies and to examine programs through a "well-being lens" (House of Commons Environmental Audit Committee, 2013-2014). Well-being questions have been added to surveys regarding crime, health behavior in school-aged children, and community learning. Agencies providing support for the longterm unemployed, welfare recipients, troubled families, and immigrants likewise use well-being data to improve services targeting such groups. The Department of Culture Media and Sport, the Arts Council, and the Department of Work and Pensions each use well-being data to improve their understanding of how their services impact well-being. These data are also used to understand how to value volunteering, occupational injuries and sickness (House of Commons Environmental Audit Committee, 2013-2014). In addition, policy makers are being trained in workshops on how to consider "the impact of proposed policy recommendations on the domains of well-being and the drivers of subjective well-being for each stakeholder" (p. 91) in the early stages of policy formation.

Another use for such data includes a pilot project for a youth program where high school students volunteer in community-building activities over the summer (Office for National Statistics, 2014a). Well-being data has been used to inform the government's alcohol policy, where findings indicate moderate consumption of alcohol is more closely correlated to a sense of well-being than excessive consumption or abstinence (INEGInforma, 2014a). There are also efforts in Wales to "make the national well-being data more accessible, engaging and relevant to local authorities and communities" (GOV.UK, 2013, p. 3). However, for the most part, the Welsh government has not yet specified exactly how the data is being used during a preliminary experimentation phase (INEGInforma, 2014a). 


\section{Appendix B}

\section{Mean Annual Income by Dzongkhag From Bhutan's National GNH 2010}

Results show Haa as a relatively lower income region, with less than half the mean annual household income than Thimphu. Self-reported income sufficiency is higher in Haa than in Thimphu.

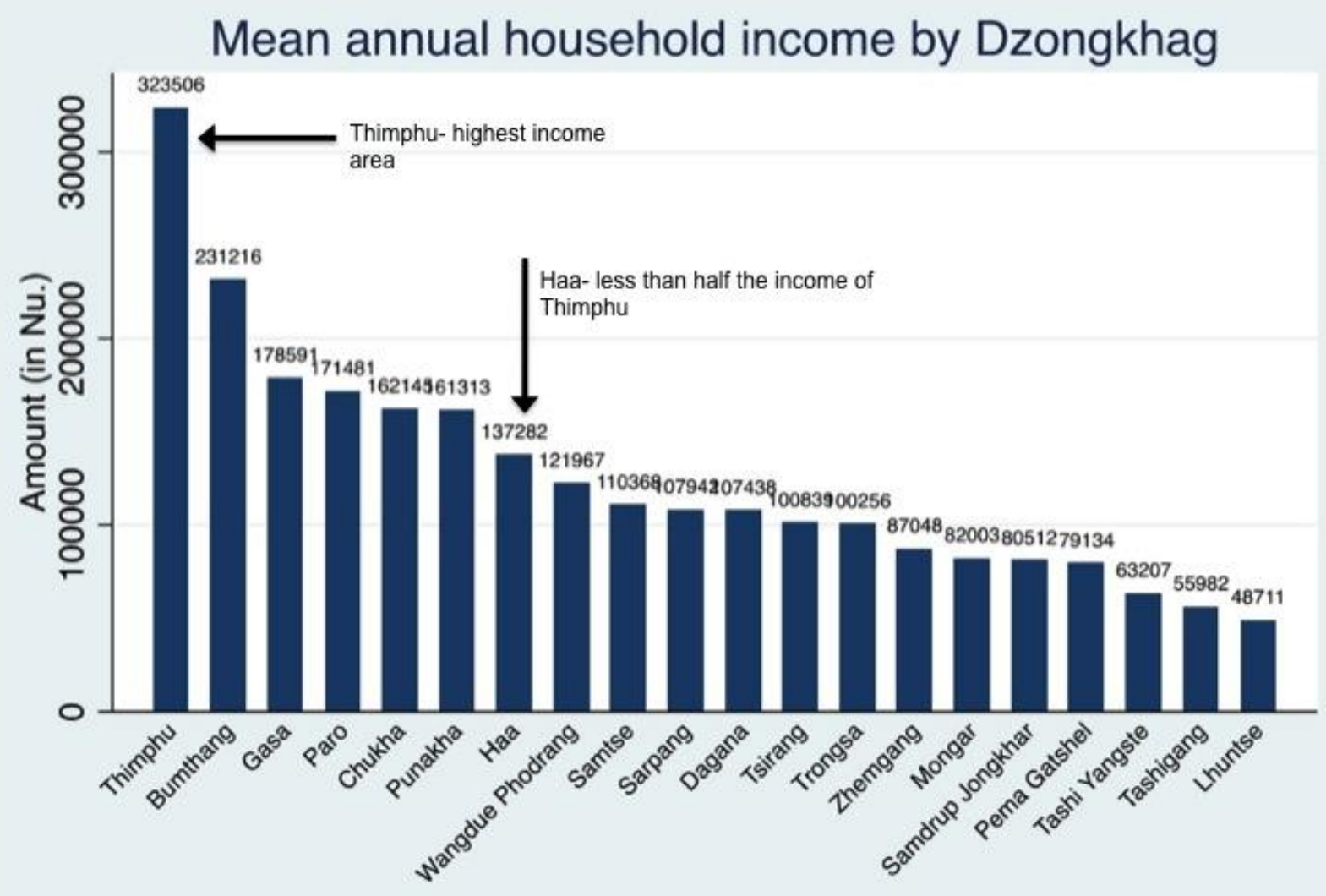

Source: GNH Survey 2010

Figure B1: Mean annual income by Dzongkhag from Bhutan's National GNH 2010. 


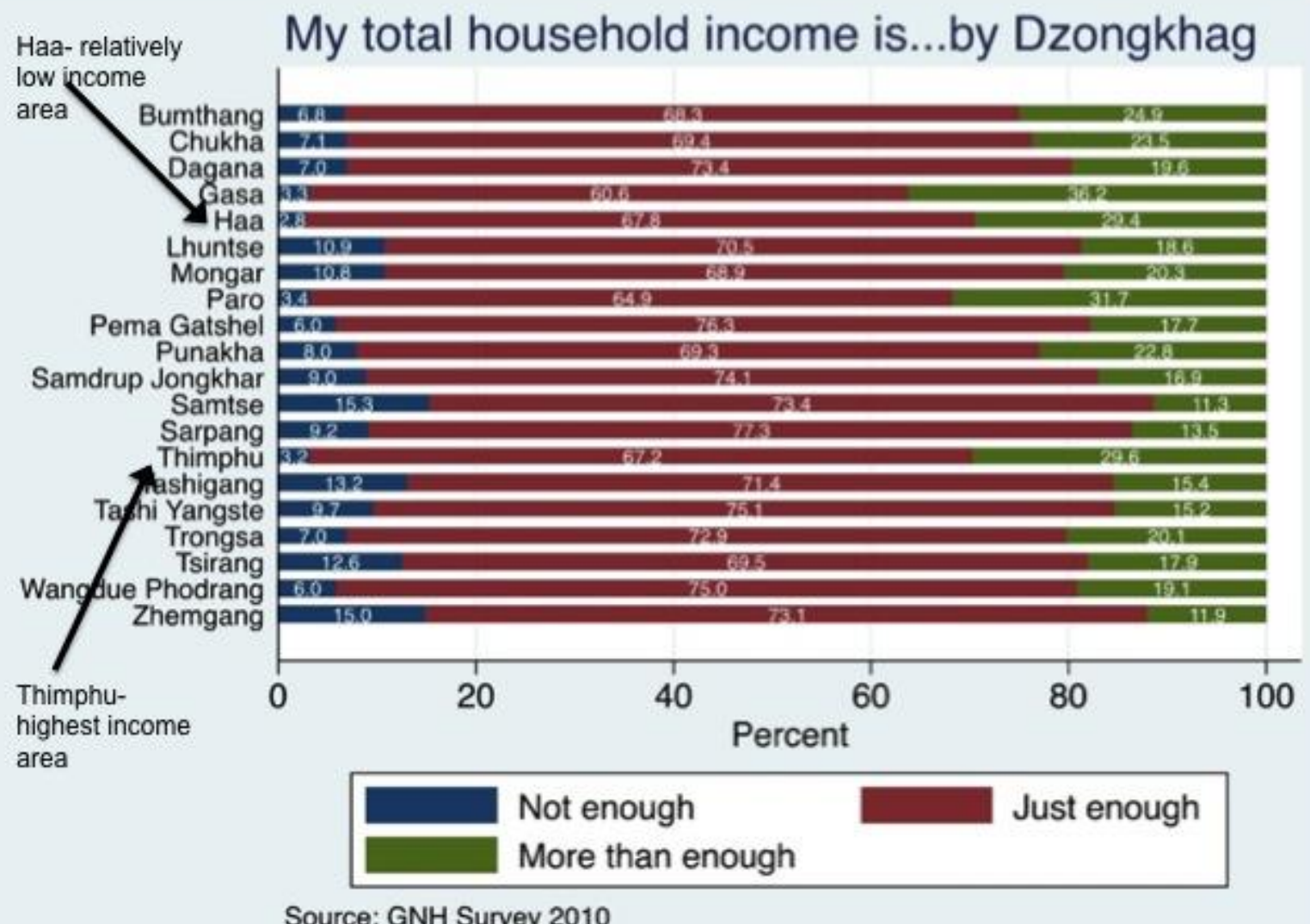

Figure B2: Mean annual income is... by Dzongkhag from Bhutan's National GNH 2010. 


\section{Appendix C}

Infographic Produced by the United Kingdom's Office of National Statistics (2014a): "Infographic Summarising Insights So Far Across Society, the Economy and the Environment From the Measuring National Well-being Programme"

\section{Measuring National Well-being: insights across society, the economy and the environment}

Measuring National Well-being (MNW) is a long term development programme. In its first three years, the MNW Programme has started to highlight the potential for using economic, environmental and social measures alongside measures of progress such as GDP, to provide a wider lens on how society is doing.

\section{Children and young people's well-being}

\section{Finding out 'what matters'}

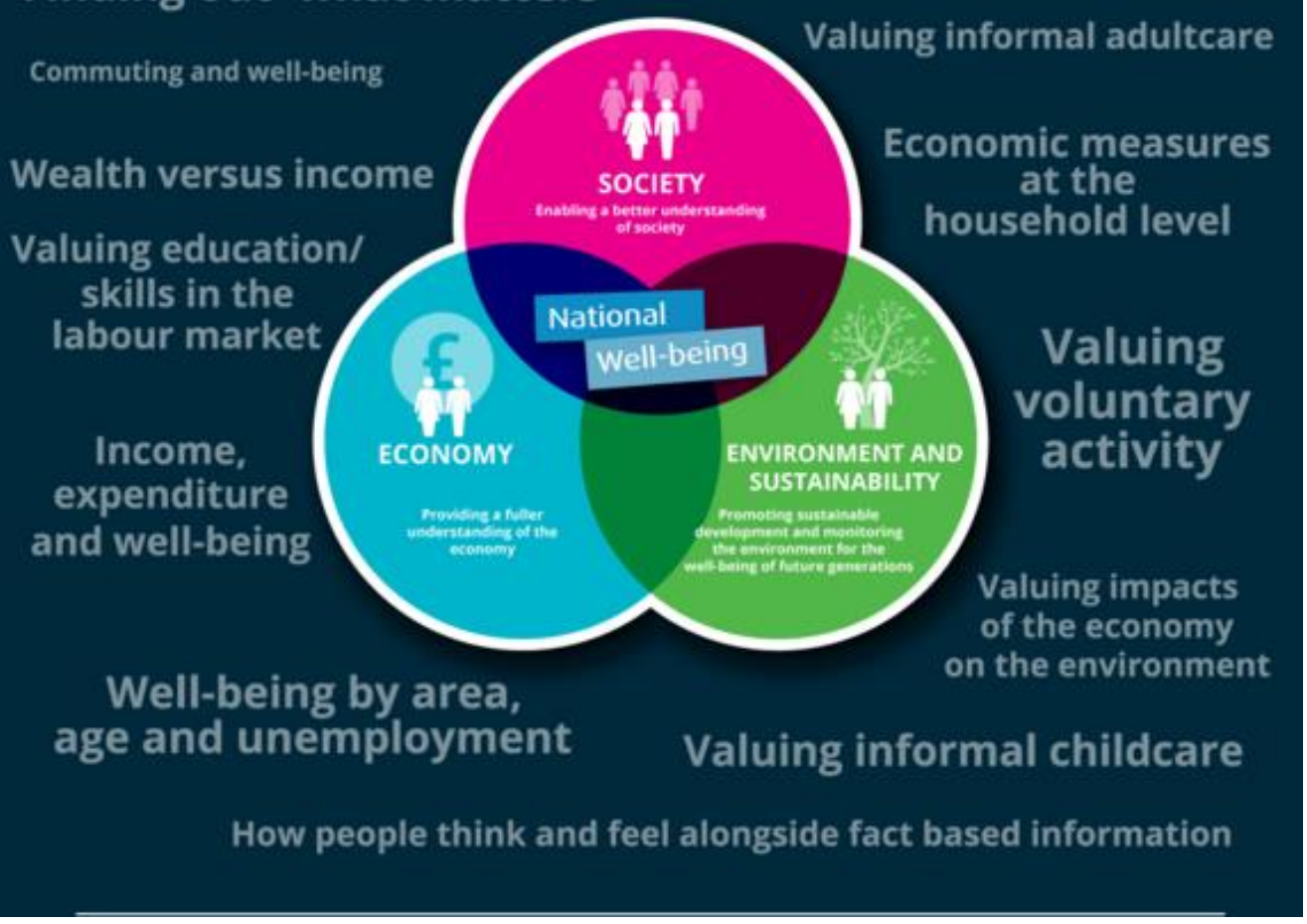

Figure C1: Infographic produced by the United Kingdom's Office of National Statistics (2014a): "Infographic Summarising Insights So Far Across Society, the Economy and the Environment From the Measuring National Well-Being Programme." 


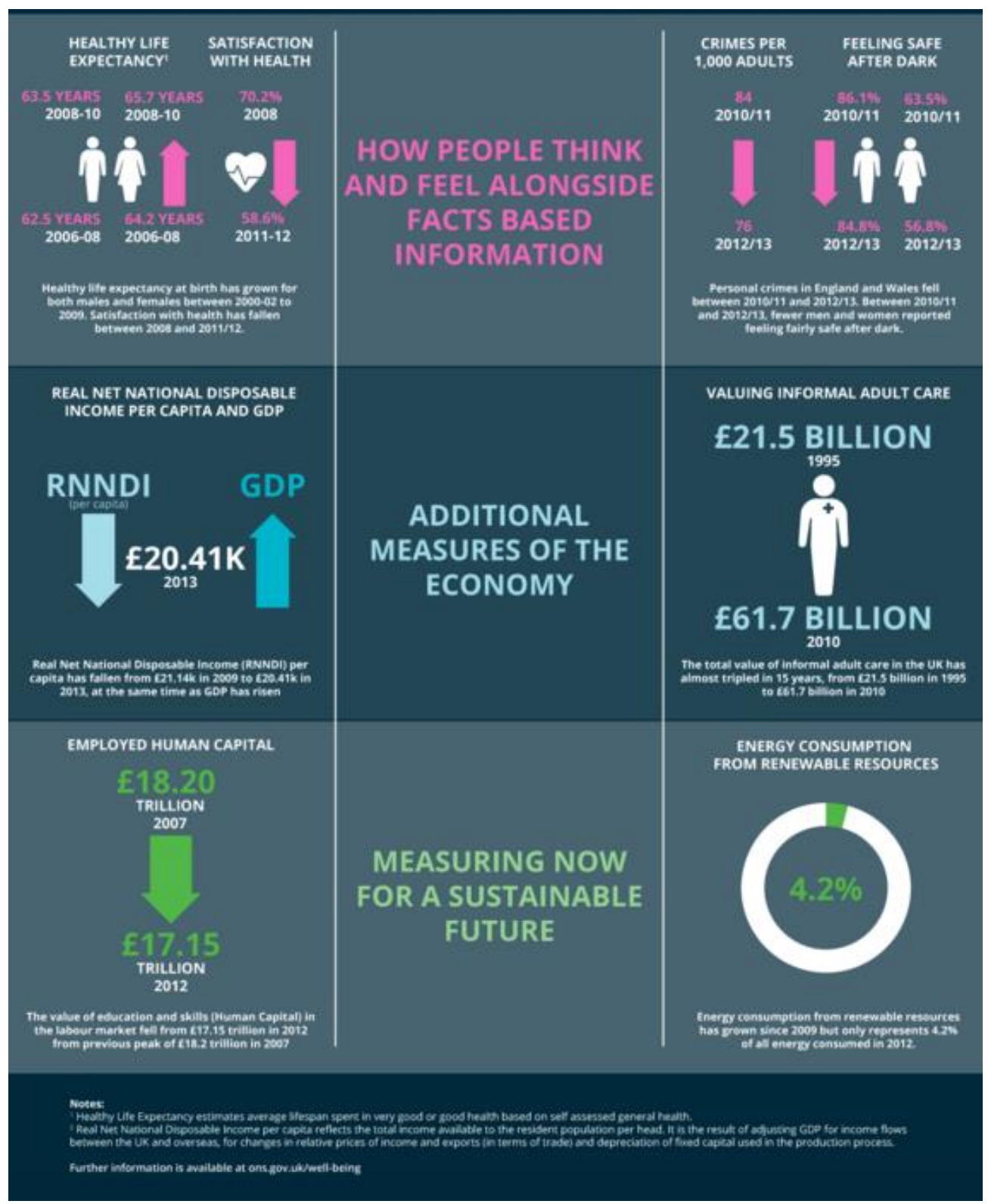

Figure C2: Infographic Produced by the United Kingdom's Office of National Statistics (2014a): "Infographic Summarising Insights So Far Across Society, the Economy and the Environment From the Measuring National Well-Being Programme." 


\title{
Appendix D
}

Personal Well-Being 3-Year Dataset Maps for the United Kingdom, Snapshot of Interactive Maps (Office for National Statistics, 2015).

\author{
Life Satisfaction \\ United Kingdom
}

How satisfied are you with your life nowadays?

$2011 / 12$ to $2013 / 14$ by local authority district, United Kingdom

Average score (out of 10 )

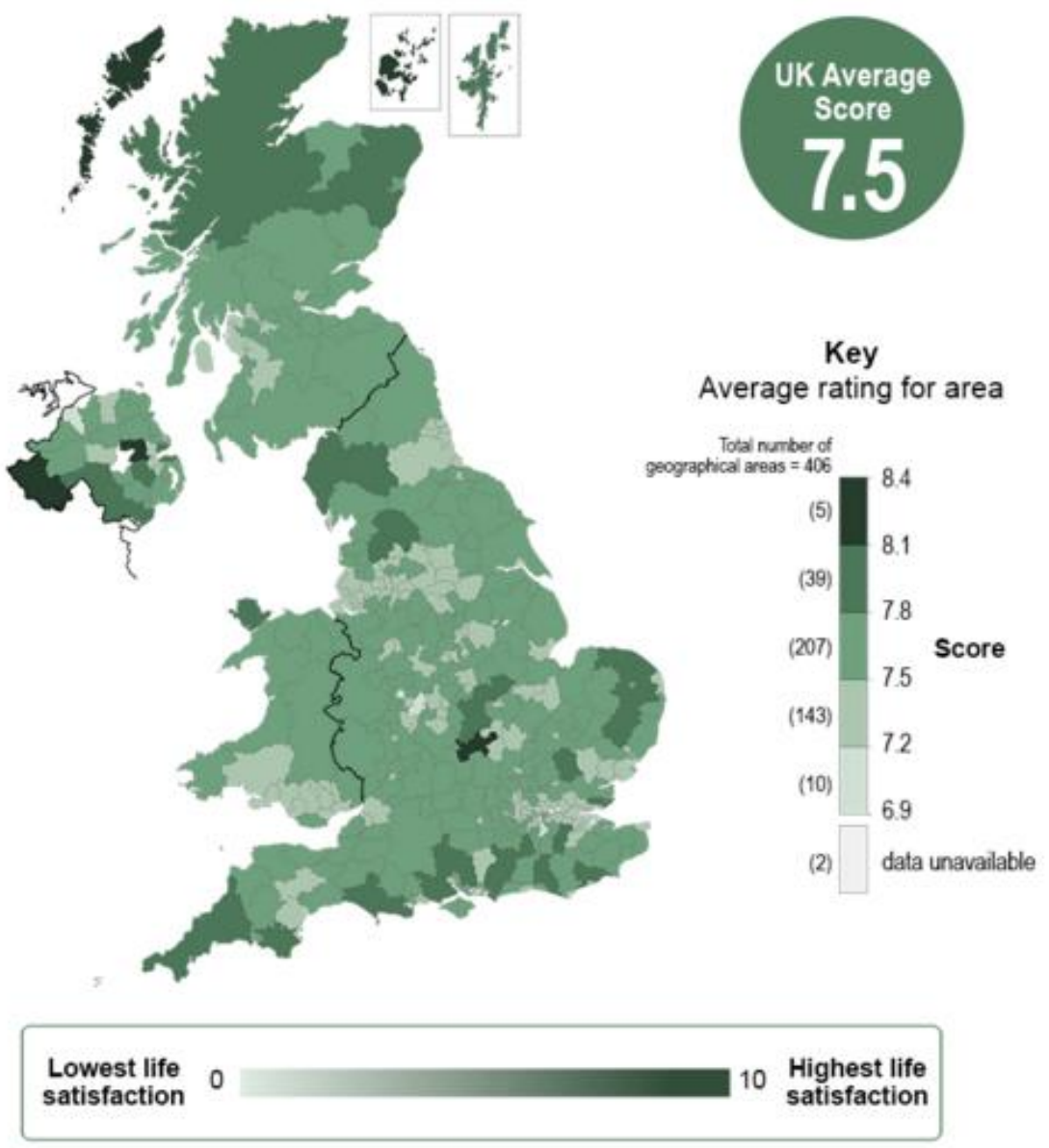

Figure D1: Life satisfaction personal well-being 3-year dataset maps for the United Kingdom. 


\section{Worthwhile}

\section{United Kingdom}

To what extent do you feel the things you do in your life are worthwhile? $2011 / 12$ to $2013 / 14$ by local authority district, United Kingdom

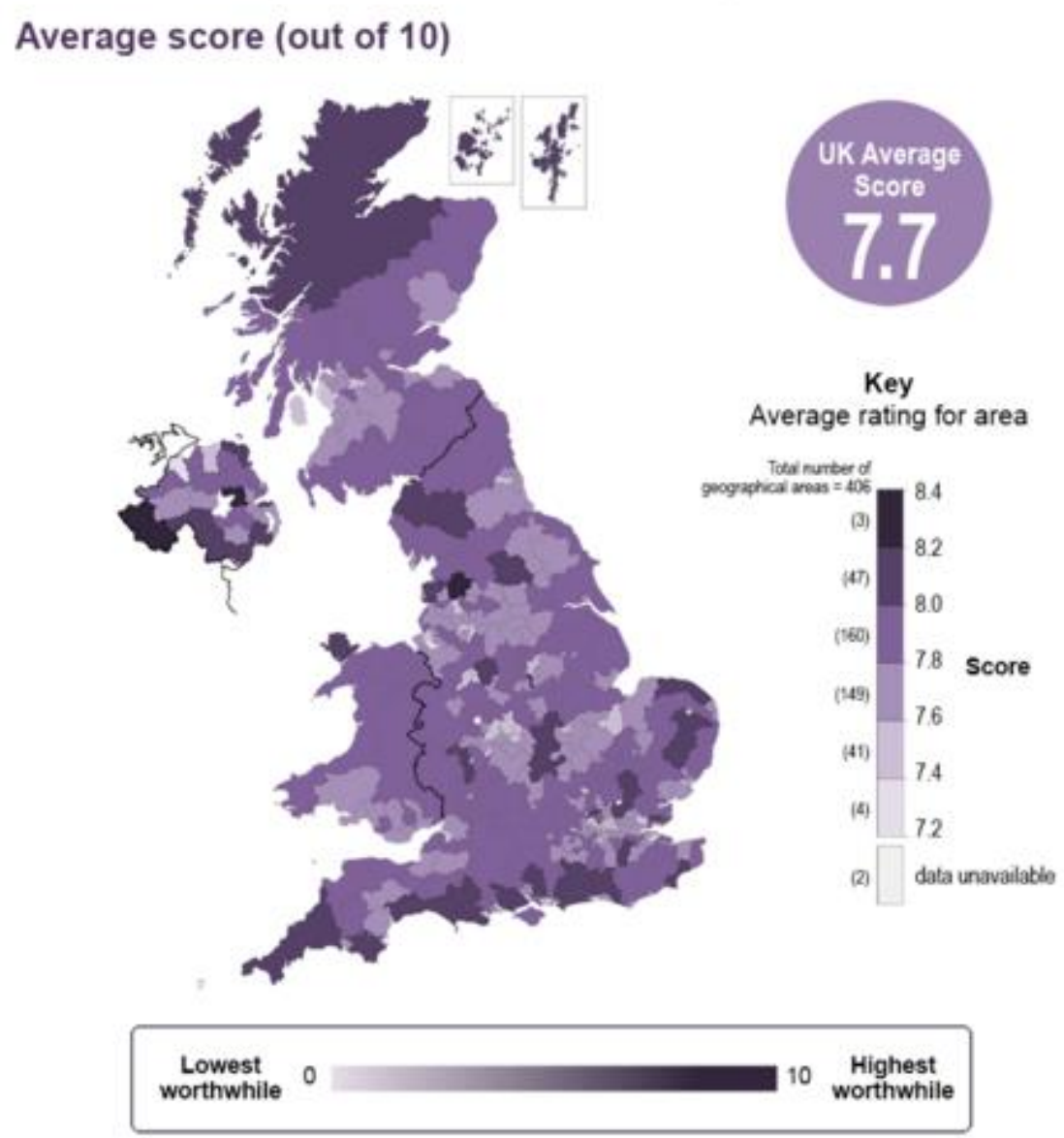

Figure D2: Worthwhile personal well-being 3-year dataset maps for the United Kingdom. 


\section{Happiness}

\section{United Kingdom}

\section{How happy did you feel yesterday?}

$2011 / 12$ to $2013 / 14$ by local authority district, United Kingdom

\section{Average score (out of 10)}

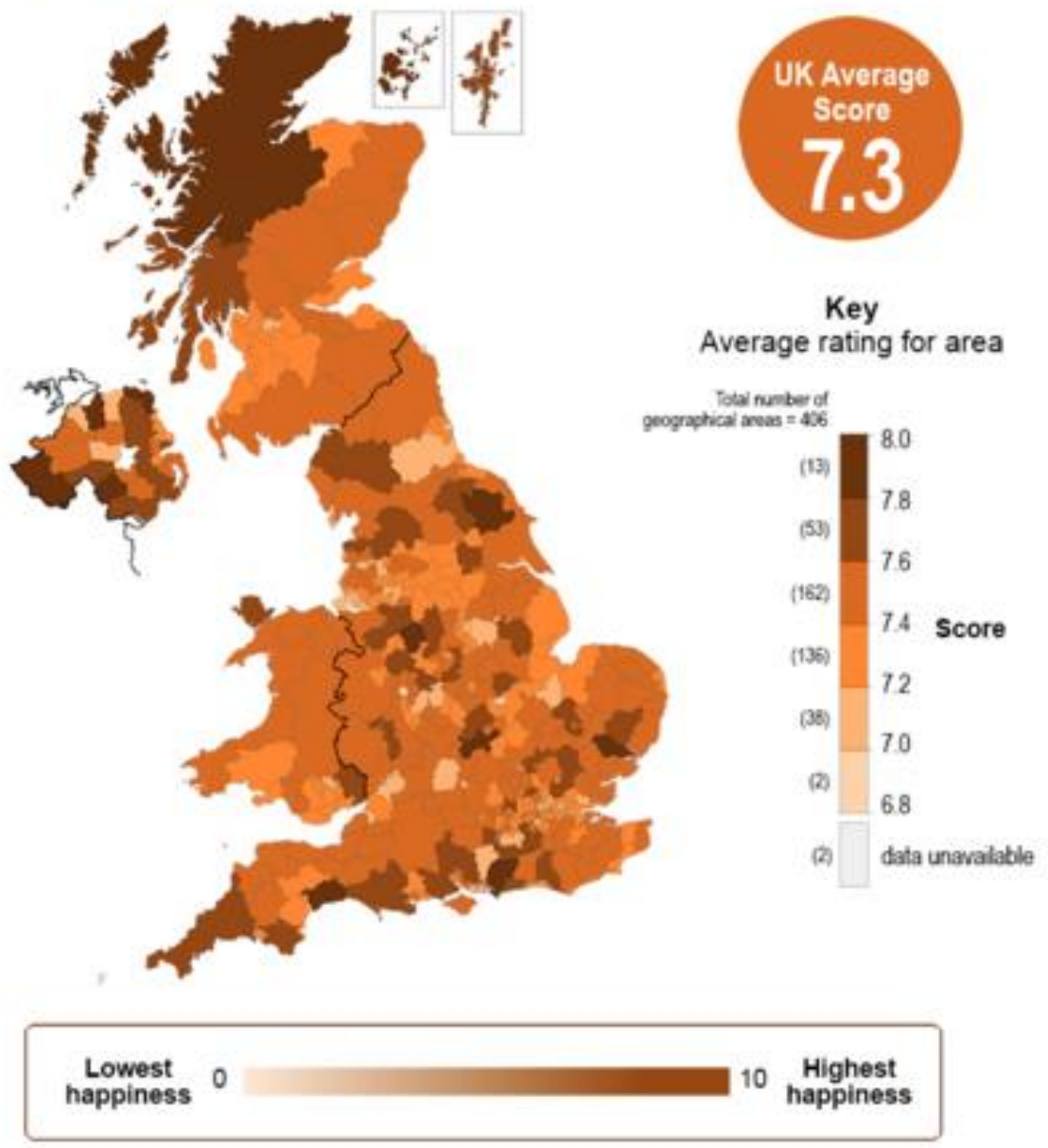

Figure D3: Happiness personal well-being 3-year dataset maps for the United Kingdom. 


\section{Anxiety}

United Kingdom

How anxious did you feel yesterday?

$2011 / 12$ to $2013 / 14$ by local authority district, United Kingdom

\section{Average score (out of 10 )}

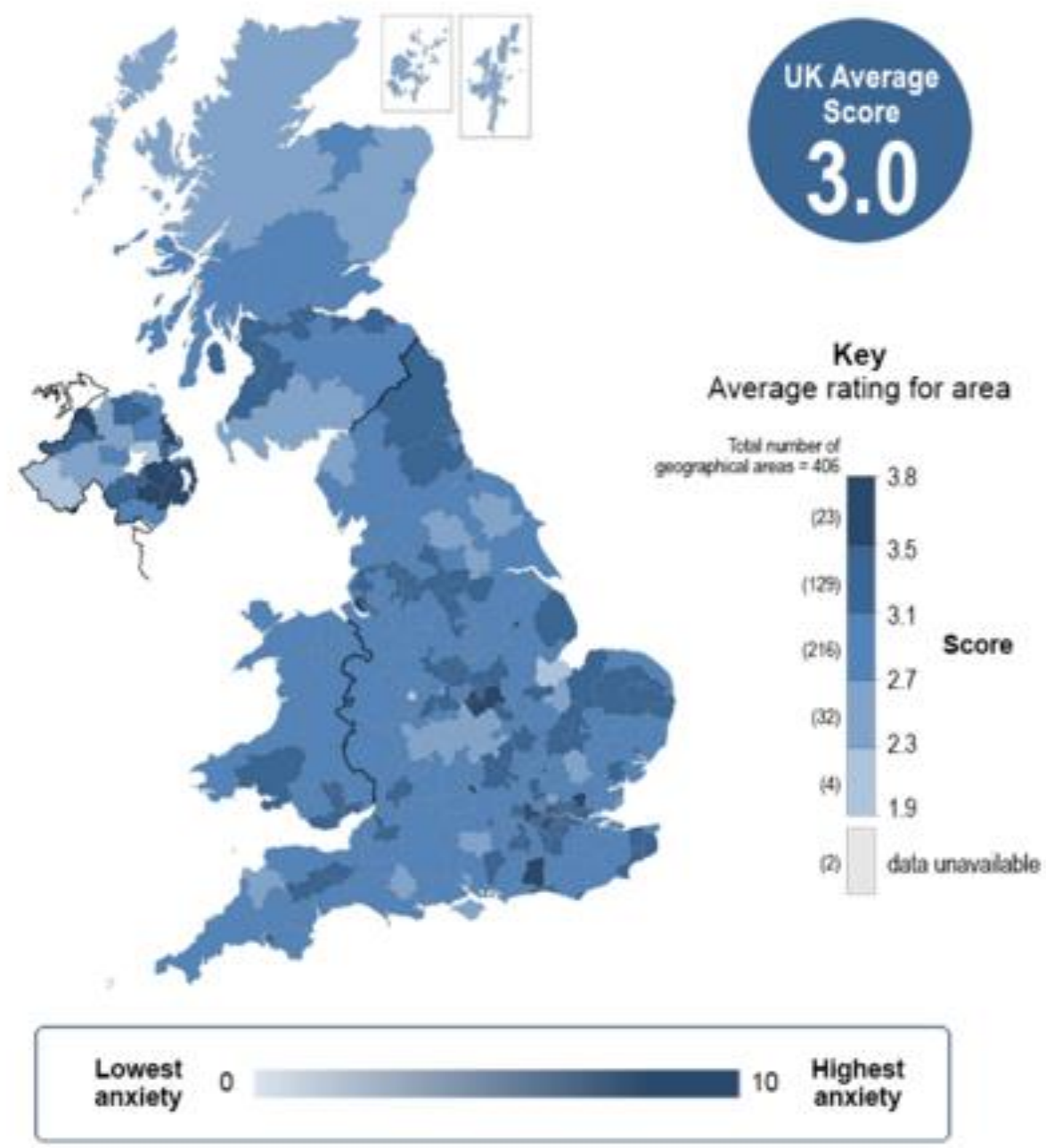

Figure D4: Anxiety personal well-being 3-year dataset maps for the United Kingdom. 
Musikanski \& Polley, 2016

\section{Appendix E}

\section{National Efforts Outside of Bhutan and the United Kingdom}

This appendix covers some of the efforts made by other national governments, aside from Bhutan and the United Kingdom discussed above, to develop and use subjective well-being metrics. Examples discussed are meant to be illustrative, not exhaustive, as the development of GNH and similar concepts of well-being are evolving and taking different forms around the world.

\section{Canada}

The Canadian government has been using subjective indicators of well-being for 25 years (Statistics Canada, 2013) and since 2003 has questions both relating to overall life satisfaction and specific to the domains of material well-being, work, leisure time and health. Statistics Canada states that its purpose in gathering this data is to "monitor changes in living conditions over time" and "provide information on specific social policy issues of current or emerging interest" (p. 6).

\section{Chile}

Because Latin Americans tend to report relatively higher levels of positive affect in comparison to peoples on other continents and in relation to their income levels, Rojas and Martinez (2012) propose that "Latin America has a lot to offer to the global study on subjective well-being" (p. 17). In Chile, some agencies are gathering subjective well-being data. According to Rojas and Martinez, the Chilean Ministry of Social Development's survey includes happiness measurements. The Chile National Socioeconomic Characterization study for September 2009 also included subjective wellbeing measurements (OPHI, 2015a). The survey included questions about overall satisfaction with life as well as food, housing, income, health, work, local security, friends, family, education, freedom of choice, dignity, community, ability to help others, and spirituality (OPHI, 2015b).

Rojas and Martinez (2012) summarize the importance of the Chilean Human Development Report in their statement that, "it is necessary to highlight the role and responsibility that the state and society as a whole can fulfill with respect to citizen's happiness" (p. 25). Gonzalez states that while the United Nation's Human Development Index for Chile included subjective well-being indicators, they are supplemental and that political support is necessary to raise their importance (INEGInforma, 2014a).

\section{China}

In China, happiness is measured using instruments both adapted from the West and created domestically. Measurement instruments borrowed from the West include the General Well-Being Schedule, the Memorial University of Newfoundland Scale, the Index of Well-Being/Index of General Affect, and the Satisfaction of Life Scale (Chen \& Davey, 2008, p. 594), as well as the International Well-Being Index developed by the International Well-Being Group (Davey \& Rato, 2012).

Instruments developed in China include the Subjective Well-Being Scale for Chinese Citizens (Xing and Huan, 2007) and Multiple Happiness Questionnaire (Miao, 2003). Both of these are similar to GNH, using 10 and nine domains, respectively. 
The national government collects systematic data in a survey called the China Household Income Project and, in 2002, this survey was revised to include questions on subjective well-being (Knight \& Gunatilaka, 2014). From 1990 to 2002, the Human Development Index as measured by the United Nations Development Programme was the main instrument for measuring life satisfaction (Lai, 2003).

\section{Italy}

In Italy, the National Council for Economics and Labour (Istat) and Italian National Institute of Statistics (CNEL) have developed sets of subjective well-being indicators through an ongoing participatory process with various stakeholders. These indicators include subjective well-being (satisfaction with life) within the context of environment, health, economy, economic well-being, education and training, landscape and cultural heritage, work and life balance, social relationships, security, research and innovation, quality of services, and policy and institutions (INEGInforma, 2014b). Subjective indicators are among the 154 indicators for which data has been gathered since 2004 (BES, 2014). A first Report on Equitable and Sustainable Well-Being uses metrics involving satisfaction with life, satisfaction with personal economic situation and satisfaction with free time to measure overall satisfaction (Istat \& CNEL, 2013; Istat, 2013). A second report further explores the concept of measuring subjective well-being with measures for satisfaction with life, leisure time and personal economic situation (Istat, 2014). Istat is refining their indicator set and developing ways for the Italian Parliament, governmental agencies and city governments to use the BES report (INEGInforma, 2014b).

\section{France}

While the French government's Stiglitz report (Stiglitz et al., 2009) has served as a catalyst in the happiness movement, the French had previously used measures that focused primarily on unhappiness (Chrisafis, 2010). In 2010, France's National Institute of Statistics and Economic Studies (INSEE) began to collect and analyze data on satisfaction with life, work, dwelling, relationships, leisure, and affect as part of its quality of life program (INSEE, 2011, p. 2). These data are used to explore issues relating to economic inequity (INSEE, 2014).

\section{Netherlands}

Northern European nations are often described in the western mainstream media as among the happiest countries in the world in large part because of the Gallup World Poll which, from 2003 to 2015, has ranked these countries among the happiest (Lallanilla, 2012). Happiness measurements have been in development and are used to varying degrees throughout Europe. The Dutch government first measured life satisfaction in 1974 with its Life Situation survey, when it began to explore measuring satisfaction across various domains of happiness: standard of living, personal health, personal achievements, personal relationships, personal safety, community connectedness, future security, and spirituality/religion (van Beuningen \& de Jonge, 2011). In the Personal WellBeing Index Construct Validity for the Netherlands report, van Beuningen and de Jonge conclude that a Personal Well-Being Index composed of such domains is valid and could be useful for policy making (2011). Research findings reported by van Beuningen, van der Houwan, and Moonan (2014, p. 20) led Statistics Netherlands to settle on a 10-point scale for measuring satisfaction with life and general affect. Statistics Netherlands reports data on male and female happiness, with longitudinal data gathered since 1997 (Statistics Netherlands, 2012, 2015). 


\section{New Zealand}

In 2008, Statistics New Zealand began to collect satisfaction with life data as part of the New Zealand General Social Survey in an effort to monitor policy (Statistics New Zealand, 2009a). In addition to overall live satisfaction, the survey covered the areas of material well-being, health, housing and neighborhoods, safety, social support, volunteering, and the environment (Statistics New Zealand, 2009b). Data was collected again in 2010 and 2012, with plans to collect additional data on civic and cultural participation in 2016 (Statistics New Zealand, 2015). Brown, Woolf, and Smith's analysis (2010) of the 2008 data concluded that, "life satisfaction provides useful and valid information about the qualities of peoples' lives [and] it can also be a used as a tool to help policymakers make decisions regarding policy alternatives...” (p. 7).

\section{Spain}

Argueso, Escudero, Mendez, and Izquierdo's (2013) report alternatives in the construction of a multidimensional quality of life indicator proposes two approaches: a composite quality of life indicator and a synthetic indicator, using data gathered by Spanish governmental agencies between 2004 and 2012. The report includes an analysis of data in an effort to understand how it can be useful in creating a single composite or synthetic indicator and how such indicators can be useful for policy purposes. The composite indicator gives equal weight to nine dimensions: material living conditions, work, health, education, social relations, insecurity (safety), governance, environment, and subjective well-being (p. 4), which are combined to calculate a single indicator. Meanwhile, the synthetic indicators are calculated on the basis of a single data source, Spain's Living Conditions Survey, which gathers data across five dimensions: material living conditions, health, education, safety and the environment (Arguesco et al., 2013, p. 34). It calculates hardship levels in a manner similar to that of Bhutan discussed above, using sufficiency thresholds.

\section{United States}

In 2013, the U.S. Census Bureau collected data on housing, community services and neighborhood conditions as part of its Household Economic Studies series (Siebens, 2013). Data are also gathered as part of the United States Census Bureau's (2012) Well-Being Program, which states that, "extended measures of well-being help deepen our knowledge about household conditions in ways not captured by money alone" (p. 1). Extended measures are divided across five areas: appliances and electronic goods, housing conditions, neighborhood conditions and community services, meeting basic needs, and social support (p. 2).

In 2012, the U.S. Bureau of Labor Statistics began to include questions about general affect (happy, tired, sad, stressed, in pain) and eudemonia as part of its American Time Use Survey (National Research Council, 2012). In 2012, overall life satisfaction data was gathered using the Cantril ladder (National Research Council, 2012, p. 13). Proposed uses for the data are to provide "relevant information on economic and social issues" and help to "improve the health and well-being of older Americans" (National Research Council, 2012). 
The Journal of Social Change, sponsored by Walden University, welcomes manuscripts focusing on interdisciplinary research in social change that improves the human condition and moves people, groups, organizations, cultures, and society toward a more positive future.

Walden University Publishing: http://www.publishing.waldenu.edu 